\title{
Brassinosteroid-mediated stress tolerance in Arabidopsis shows interactions with abscisic acid, ethylene and salicylic acid pathways
}

\author{
Uday K Divi, Tawhidur Rahman and Priti Krishna*
}

\begin{abstract}
Background: Brassinosteroids (BRs) play crucial roles in plant development and also promote tolerance to a range of abiotic stresses. Although much has been learned about their roles in plant development, the mechanisms by which BRs control plant stress responses and regulate stress-responsive gene expression are not fully known. Since BR interacts with other plant hormones, it is likely that the stress tolerance conferring ability of BR lies in part in its interactions with other stress hormones.

Results: Using a collection of Arabidopsis mutants that are either deficient in or insensitive to abscisic acid (ABA), ethylene (ET), jasmonic acid (JA) and salicylic acid (SA), we studied the effects of 24-epibrassinloide (EBR) on basic thermotolerance and salt tolerance of these mutants. The positive impact of EBR on thermotolerance in proportion to wild type was evident in all mutants studied, with the exception of the SA-insensitive npr1-1 mutant. EBR could rescue the ET-insensitive ein 2 mutant from its hypersensitivity to salt stress-induced inhibition of seed germination, but remained ineffective in increasing the survival of eto 1-1 (ET-overproducer) and npr1-1 seedlings on salt. The positive effect of EBR was significantly greater in the ABA-deficient aba 1-1 mutant as compared to wild type, indicating that $A B A$ masks BR effects in plant stress responses. Treatment with EBR increased expression of various hormone marker genes in both wild type and mutant seedlings, although to different levels.

Conclusions: These results together indicate that the redox-sensitive protein NPR1 (NONEXPRESSOR OF PATHOGENESIS-RELATED GENES1), a master regulator of SA-mediated defense genes, is likely a critical component of EBR-mediated increase in thermotolerance and salt tolerance, but it is not required for EBR-mediated induction of PR-1 (PATHOGENESIS-RELATED1) gene expression; that BR exerts anti-stress effects independently as well as through interactions with other hormones; that ABA inhibits BR effects during stress; and that BR shares transcriptional targets with other hormones.
\end{abstract}

\section{Background}

Brassinosteroids (BRs) are a group of plant steroidal hormones that regulate various aspects of plant growth and development, including cell elongation, photomorphogenesis, xylem differentiation, and seed germination [1], as well as adaptation to abiotic and biotic environmental stresses [2,3]. Molecular genetic studies of BR-deficient and BR-insensitive mutants have established an essential role for BRs in plant development and led to the identification and characterization of several BR signaling com-

* Correspondence: pkrishna@uwo.ca

1 Department of Biology, University of Western Ontario, London, ON, N6A 5B7, Canada

Full list of author information is available at the end of the article ponents [4,5]. A large number of BR-regulated genes have been identified by microarray studies; most of the known BR-regulated genes are associated with plant growth and development, such as cell wall modification, cytoskeleton formation, and hormone synthesis [4]. How BR regulates gene expression is currently understood for only a small proportion of genes. In the current model of BR-controlled gene expression, BR binding to BRI1, a plasma membrane localized leucine-rich repeat receptor-like kinase (LRR-RLK), induces association of BRI1 with its coreceptor BAK1, which enhances signaling output through reciprocal BRI1 transphosphorylation $[4,5]$. BRI1 binding to BR inactivates BIN2, a glycogen synthase kinase-3, and possibly activates the phosphatase BSU1. 
BIN2 negatively regulates transcription factors BZR1 and BES1 by phosphorylating them, while BSU1 positively regulates $B R$ signaling by dephosphorylating BZR1 and BES1. Activated BZR1 and BES1 accumulate in the nucleus and directly bind to CGTG(T/C)G motif in the promoters of BR biosysnthesis genes CPD and DWF4 [6] and to E box sequence (CANNTG) in the SAUR-ACI promoter [7], respectively, to affect gene expression. The recent demonstrations that BES1 interacts with other transcription factors such as BIMs [7], MYB30, which acts as a positive regulator of the hypersensitive cell death response [8], and the jumonji (Jmj) domain-containing proteins ELF6 and REF6 that are involved in regulating flowering time [9], points to recruitment of different proteins by BES1 as one of the ways by which BR affects diverse biological processes.

The role of BRs in plant stress responses has been confirmed in several studies [10-13]. BR promotes tolerance in plants to a wide range of stresses, including heat, cold, drought and salinity, and this increase is generally correlated with higher expression of stress marker genes, such as heat shock protein ( $h s p$ ) genes, RD29A and ERD10 $[10,12]$, indicating that increased expression of stressresponsive genes is responsible, in part, for the higher stress tolerance in BR-treated plants. The mechanisms by which BR controls plant stress responses and regulates the expression of stress response genes are not known. Since different plant hormones can regulate similar physiological processes, and cross-talk between different hormones can occur at the level of hormone biosynthesis, signal transduction or gene expression [14], it was proposed that BR regulates plant stress responses via crosstalk with other hormones [2].

The plant growth regulators with documented roles in plant adaptation to abiotic and biotic stresses are abscisic acid (ABA), ethylene (ET), jasmonic acid (JA) and salicylic acid (SA). SA, JA and ET are important in defense against pathogen and pest attack [15], whereas ABA is a key molecule involved in salt and drought stress [16]. SA, ET, ABA and JA have also been linked to heat stress. Studies of hormone deficient and insensitive mutants have demonstrated the involvement of SA, ET and ABA in acquired thermotolerance of plants [17], and additionally for SA and JA, a role in basal thermotolerance of plants $[18,19]$. Although experimental evidence points to interactions of BR with auxin [20], gibberellin (GA) [21], ABA [22,23], ET [24,25] and JA [26], the relationship of BR with these hormones has been documented primarily in plant growth regulatory processes. Furthermore, with the exception of BR-auxin interaction, little is known in terms of genes how BR interacts with other hormones. Recent progress made towards understanding BR-auxin interaction can serve as a paradigm for how two hormones could interact at multi-levels. Auxin and BR share a number of target genes, many of which are involved in growth-related processes [20]. Since promoter regions in $\mathrm{BR}$-responsive genes are enriched in Auxin Response Factor (ARF)-binding sites, and binding sites of BES1 are overrepresented in genes regulated by both hormones, regulatory elements in gene promoters represent a point of cross-talk between auxin and BR. Recently, the BR-regulated BIN2 kinase was demonstrated to phosphorylate ARF2, a member of the ARF family of transcriptional regulators, leading to loss of ARF2 DNA binding and repression activities [27]. Thus, in this model ARF2 links BR and auxin signaling pathways. In addition to gene coregulation, BR can also promote auxin transport [28], and optimal auxin action is dependent on BR levels [20].

The role of BR in plant responses to abiotic stress has become well established over the last decade, but there are very few reports indicating how BR interacts with other stress-related hormones and their signaling pathways in conferring stress tolerance. While there exists evidence to indicate that BR increases ET and JA levels under normal growth conditions [24,29], there appears to be only one report linking $\mathrm{BR}$ with increase in $\mathrm{ABA}$ levels in the lower plant Chlorella vulgaris under stress condition [30]. Recently it was demonstrated that ABA inhibits $\mathrm{BR}$ signaling through phosphorylation of BES1 [23]. Currently there are no studies at the genetic level as to how BR interacts with other hormones under stress conditions. Here we asked the question whether one or more stress-related hormones, such as ABA, ET, JA or SA, have a major role in BR-mediated stress tolerance. Arabidopsis mutants with either disrupted or enhanced hormone pathways were tested for phenotypes and gene expression in response to BR under high temperature and high salt conditions. Our results suggest that in Arabidopsis the NONEXPRESSOR OF PATHOGENESIS-RELATED GENES1 (NPR1) is likely a critical component of BRmediated effects on thermotolerance and salt tolerance, that BR exerts anti-stress effects both independently as well as through interactions with other hormones, ABA inhibits BR effects during heat stress, and that BR shares transcriptional targets with other hormones.

\section{Results}

EBR effects on basal thermotolerance in different hormone genotypes

We have previously demonstrated that EBR enhances the basic thermotolerance of Brassica napus, tomato [10,11] and Arabidopsis seedlings [12]. Since the effects of EBR on stress tolerance are most pronounced when seedlings are grown in the presence of EBR (long-term treatment), we postulated the involvement of other phytohormones in this process [2]. Several hormone pathways, such as of ABA, ET, SA and JA, have been linked with one or more environmental stresses, including heat stress (HS). We 
therefore evaluated the effects of EBR on thermotolerance in a subset of Arabidopsis hormone mutants altered in either biosynthesis or signaling of these phytohormones (Table 1). We first studied the effects of EBR on basal thermotolerance in SA genotypes npr1-1 (defective in signalling for SA-mediated systemic acquired resistance (SAR), but not all SA responses), eds5-1 (defective in SA synthesis), and cpr5-2 (elevated SA levels, enhanced levels of $P R$, and constitutive expression of both NPR1dependent and NPR1-independent SAR pathway) by exposing 21-day-old seedlings to $43^{\circ} \mathrm{C}$ for $4 \mathrm{~h}$, allowing them to recover at $22^{\circ} \mathrm{C}$ for 7 days and then scoring for dead and surviving seedlings. WT, eds5-1, npr1-1 and cpr 5-2 seedlings grown in the absence of EBR had average survival rates of 7.5, 4.5, 5.5 and $13.5 \%$, respectively, and those grown in the presence of EBR had survival rates of $69.3,58.3,13.4$ and $83 \%$, respectively (Figure $1 \mathrm{~A}$ and $1 \mathrm{C}$ ). From these results it is clear that the survival rates of WT and different SA genotypes were significantly increased by EBR treatment, but the increase was considerably less in case of $n p r 1-1$ as compared to other genotypes within this group. Photographs of all genotypes grown in the presence or absence of EBR under no-stress conditions can be seen in additional file 1: Pictures of 21-day-old seedlings.

For genotypes related to ethylene, EBR increased survival rates of WT, ein2 (ET-insensitive), and eto1-1 (EToverproducer) seedlings to significant levels as compared to seedlings with no treatment (Figure 1D).

The JA mutants aos (JA-deficient) and jar1-1 (defective in JA response) belong to different backgrounds; jar1-1 is in Arabidopsis ecotype Columbia (Col), whereas aos is in Col-6 background. EBR increased survival rates of aos and jar1-1 seedlings to amounts similar to corresponding WT seedlings (Figure 1E).

The ABA mutants aba1-1 (ABA-deficient) and abil-1 (ABA-insensitive) are from the Landsberg erecta (Ler) background; hence, WT Ler was used for comparison with these mutants. Under the conditions used, EBR was less effective in WT Ler as compared to WT Col (about 2.5-fold increase in Ler vs 9-fold increase in Col in survival rates in response to $\mathrm{EBR}$ ) (Figure $1 \mathrm{E}$ and $1 \mathrm{~F}$ ). Since $\mathrm{ABA}$ has been linked with heat tolerance $[17,31]$, we expected ABA mutants to be less thermotolerant than WT even in the presence of EBR. Contrary to our expectation we found that the effect of EBR was most distinct in aba1-1 (survival rate of $43.3 \%$ ) as compared to WT (14.3\%) and abi1-1 (15\%) seedlings (Figure 1B and 1F). These results suggest that ABA masks $B R$ effects on the HS response pathway of WT Arabidopsis seedlings.

From the survival data represented in Figure 1 it is clear that when EBR effect in any hormone genotype is viewed in reference to the effect on the corresponding WT, EBR could increase the basal thermotolerance of all hormone genotypes, but its effect was minimal in npr1-1. Since the SA-deficient NahG transgenic line [32] and the JA response defective coil mutant [33] could not be obtained for this study, we cannot yet conclude that SA and JA are dispensable for BR-mediated increase in thermotolerance. However, from the collection of mutants used here it would appear that BR can exert anti-stress effects that are independent of ABA, ET, JA and SA, at least to some extent. The dependency of BR on NPR1 in mediating stress tolerance is a first time observation made in this study. Whether BR modulates NPR1 activity via SA or BR pathway or both remains to be determined.

\section{EBR effects on oxidative damage in hormone mutants}

Heat stress produces oxidative damage, which as a result of lipid peroxidation leads to the production of thiobarbituric acid reactive substances (TBARS) [17,34]. To complement the results of the HS phenotype of seedlings, oxidative damage levels were assessed in untreated and EBR-treated seedlings. Measurements of TBARS in time course experiments determined that maximum oxidative damage occurred during recovery from HS (data not shown). Therefore, seedlings exposed to HS and then allowed to recover for 2 days at $22^{\circ} \mathrm{C}$ were used for TBARS analysis. With the exception of npr1-1 and cpr52, EBR treatment reduced the levels of oxidative damage in WT and other mutant seedlings as compared to their untreated counterparts (Figure 2A). WT Col and Ler exhibited $45 \%$ and $60 \%$ reduction in TBARS production, respectively, while the mutant seedlings showed $25-50 \%$ less TBARS, in response to EBR treatment. Consistent with its lower survival rate (Figure 1), the npr1-1 mutant showed an insignificant $4.5 \%$ reduction in TBARS production in response to EBR treatment (Figure 2A). However, in contrast to the relatively higher survival of $c p r 5-2$ seedlings, the reduction in oxidative damage in these seedlings in response to EBR measured only $25 \%$ relative to no treatment. Overall, these results demonstrated that EBR treatment can reduce oxidative damage during HS and that this effect is not critically dependent on any one hormone in question, although a functional NPR1 protein appears to be required for a complete effect of EBR on thermotolerance of seedlings.

\section{EBR induces higher accumulation of hsp90 in aba 1-1}

We have found that EBR treatment leads to significant increases in the levels of hsps during $\mathrm{HS}$ in B. napus $[10,11]$, but the effect of EBR on hsp levels in Arabidopsis is subtle [12]. We wished to see how EBR would affect the accumulation of hsp90 in various mutant seedlings in the absence of $\mathrm{HS}\left(22^{\circ} \mathrm{C}\right)$ and in response to HS $(3 \mathrm{~h}$ and $4 \mathrm{~h}$ exposure to $43^{\circ} \mathrm{C}$ ). With the exception of aba1-1 (Figure 2B), no significant differences in the steady state levels of hsp90 were observed between EBR-treated and untreated mutant seedlings, including nprl-1 (data not shown). 
A

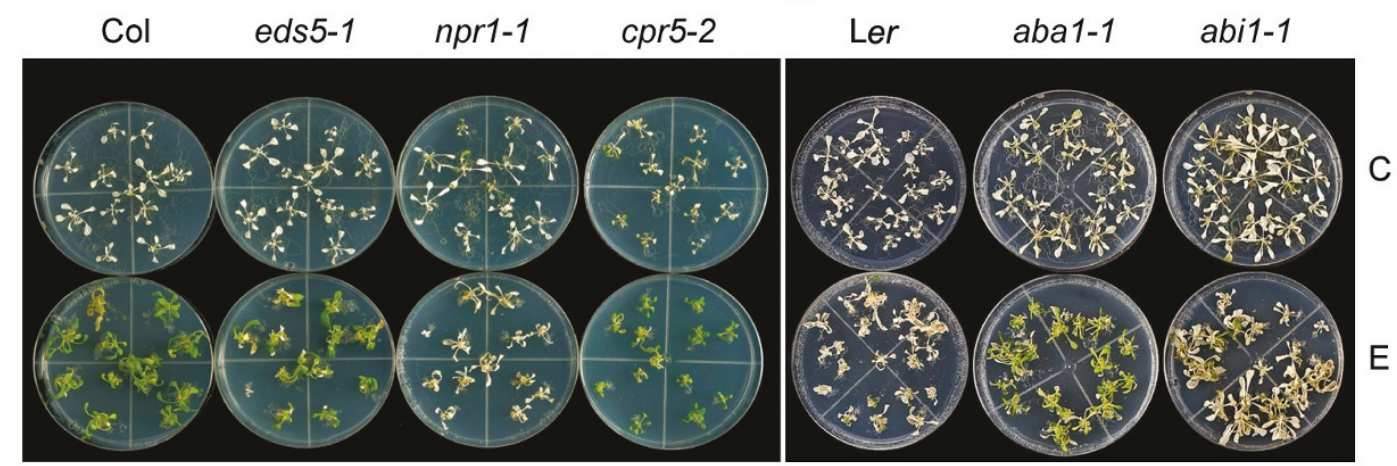

C
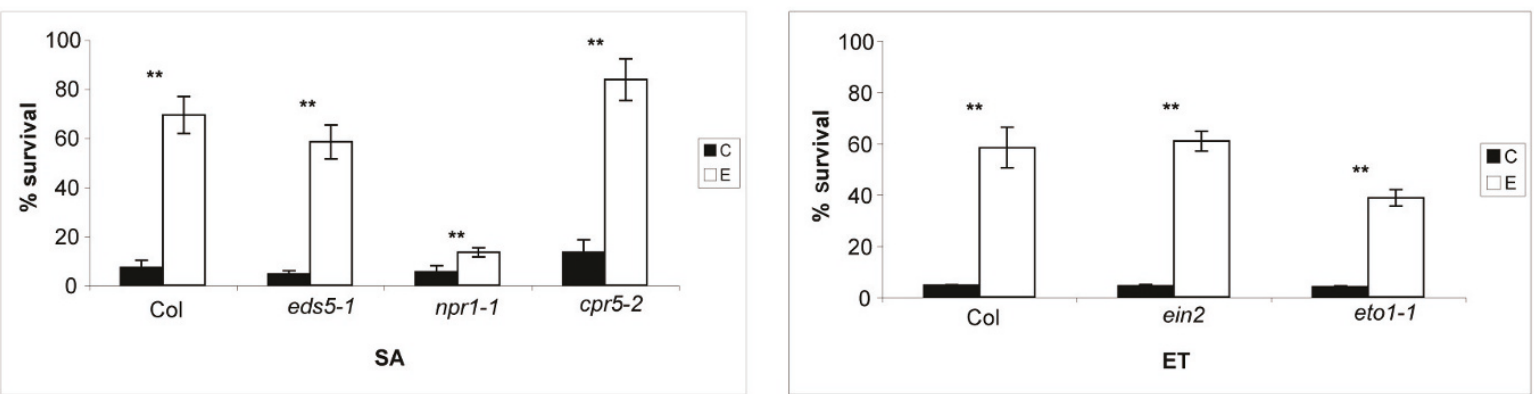

E

$\mathrm{F}$
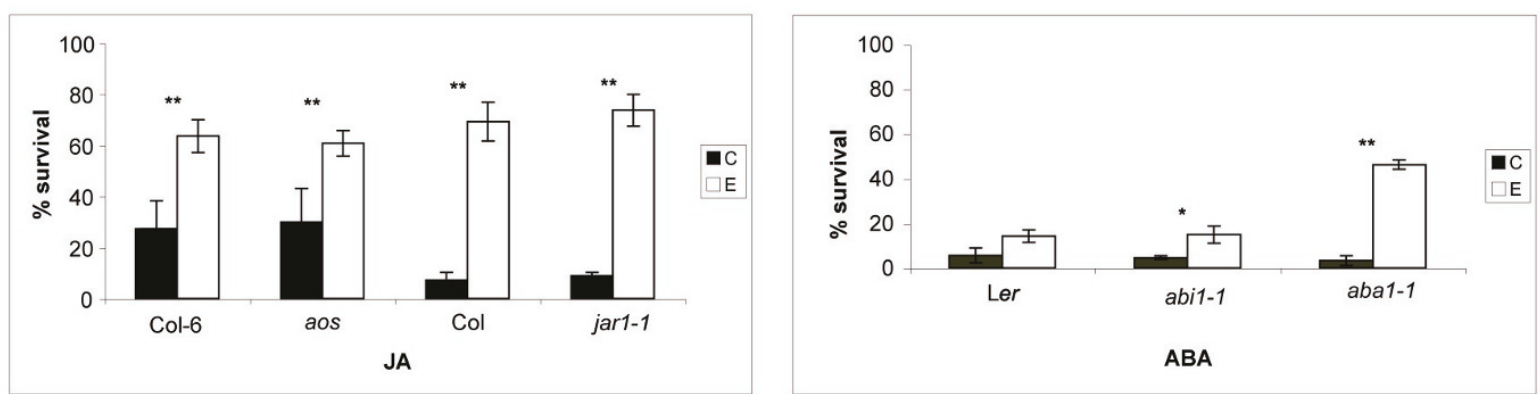

Figure 1 Effect of EBR treatment on basal thermotolerance of Arabidopsis WT and SA, ET, JA and ABA mutant seedlings. (A and B) WT and mutant seedlings grown on a nutrient medium in the absence (C) or presence of $1 \mu \mathrm{M} \mathrm{EBR}$ (E) were exposed to $43^{\circ} \mathrm{C}$ for $4 \mathrm{~h}$. Photographs of the seedlings were taken after recovery at $22^{\circ} \mathrm{C}$ for 7 days. (C-F) Proportion of WT and mutant seedlings surviving the lethal heat stress $\left(43^{\circ} \mathrm{C}\right.$ for $\left.4 \mathrm{~h}\right)$. Seedlings grown and treated as described in methods were scored as dead or surviving after 7 days of recovery at $22^{\circ} \mathrm{C}$. WT controls were Lerfor abil-1 and $a b a$ 1-1, Col-6 for aos, and Col for all other mutants. Data shown are average of three replicates. Error bars represent standard error (SE) of mean for three replicates. Asterisks above the histograms indicate the significance of differences between untreated and EBR-treated genotypes as analyzed by Student's t-test $\left({ }^{* *} p<0.01 ;{ }^{*} p<0.05\right)$.

EBR-treated aba1-1 seedlings accumulated approximately 3 - and 2.5-fold higher levels of hsp90 at 3 and $4 \mathrm{~h}$ of HS, respectively, as compared to untreated aba1-1 seedlings (Figure 2B). By contrast, EBR-treated WT seedlings showed a maximum of 1.3-fold increase in hsp90 levels at $4 \mathrm{~h}$ of HS as compared to untreated seedlings. The fold-change values are average of three different experiments, which consistently produced the same pattern of protein accumulation. Thus, with respect to higher survival following HS and greater accumulation of hsp90 during HS, EBR produced most distinct effects in the ABA-deficient aba1-1 mutant. These results reinforce the idea that ABA suppresses BR effects in WT seedlings. Although convincing evidence for antagonism between $\mathrm{BR}$ and $\mathrm{ABA}$ in plant growth regulatory processes, such as germination has been provided before $[22,23]$, the demonstration at the genetic and molecular levels of an antagonistic relationship between the two hormones in plant stress response is new. 
Table 1: Mutant alleles used in the study with the description of corresponding genes and mutant phenotypes

\begin{tabular}{|c|c|c|c|c|c|}
\hline Category & Locus (AGI) & Gene & Description & $\begin{array}{c}\text { Mutant allele } \\
\text { used }\end{array}$ & References \\
\hline $\begin{array}{l}\text { SA synthesis } \\
\text { Defective }\end{array}$ & AT4G39030 & EDS5 & $\begin{array}{l}\text { member of the MATE-transporter family; } \\
\text { mutants do not accumulate SA after pathogen inoculation and are } \\
\text { hypersusceptible to pathogen infection. }\end{array}$ & eds5-1 & {$[73,74]$} \\
\hline SA-insensitive & AT1G64280 & $N P R 1$ & $\begin{array}{l}\text { similar to the transcription factor inhibitor I kappa B, and contains } \\
\text { ankyrin repeats; } \\
\text { key regulator of SA-mediated systemic acquired } \\
\text { resistance (SAR) pathway; } \\
\text { mutants are SA-insensitive and hypersusceptible } \\
\text { to pathogen infection. }\end{array}$ & npr1-1 & {$[43,75,76]$} \\
\hline High SA levels & AT5G64930 & CPR5 & $\begin{array}{l}\text { regulator of expression of pathogenesis-related }(P R) \text { genes; } \\
\text { participates in signal transduction pathways involved in plant defense; } \\
\text { mutants exhibit increased SA levels and constitutive expression of } P R \\
\text { genes. }\end{array}$ & cpr5-2 & [63] \\
\hline ET-insensitive & AT5G03280 & EIN2 & $\begin{array}{l}\text { NRAMP metal transporter family; involved in ET signal transduction; } \\
\text { mutants are ET-insensitive. }\end{array}$ & ein2 & [77] \\
\hline High ET levels & AT3G51770 & ETO1 & $\begin{array}{l}\text { encodes a negative regulator of 1-aminocyclopropane-1-carboxylic } \\
\text { acid synthase5(ACS5), which catalyzes the rate-limiting step in ET } \\
\text { biosynthesis; } \\
\text { mutations elevate ET biosynthesis by affecting the posttranscriptional } \\
\text { regulation of ACS. }\end{array}$ & eto 1-1 & {$[77]$} \\
\hline JA-deficient & AT5G42650 & $A O S$ & $\begin{array}{l}\text { encodes a member of the cytochrome p } 450 \text { CYP74 gene family that } \\
\text { functions as an allene oxide synthase; } \\
\text { catalyzes dehydration of the hydroperoxide to an unstable allene oxide } \\
\text { in the JA biosynthetic pathway; } \\
\text { mutants are JA-deficient. }\end{array}$ & aos & {$[78]$} \\
\hline JA-insensitive & AT2G46370 & $J A R 1$ & $\begin{array}{l}\text { encodes cytoplasmic localized phytochrome A signaling component } \\
\text { protein similar to the GH3 family of proteins; } \\
\text { loss of function mutants are defective in a variety of responses to JA. }\end{array}$ & jar1-1 & [79] \\
\hline ABA-deficient & AT5G67030 & $A B A 1$ & $\begin{array}{l}\text { encodes zeaxanthin epoxidase gene that functions in first step of ABA } \\
\text { biosynthesis; } \\
\text { mutants are ABA-deficient. }\end{array}$ & $a b a 1-1$ & {$[80]$} \\
\hline ABA-insensitive & AT4G26080 & $A B I 1$ & $\begin{array}{l}\text { Protein phosphatase } 2 \mathrm{C} \text {; involved in } \mathrm{ABA} \text { signal transduction; } \\
\text { mutants are } \mathrm{ABA} \text {-insensitive. }\end{array}$ & $a b i 1-1$ & {$[81]$} \\
\hline
\end{tabular}

EBR upregulates the expression of SA, JA/ET and ABAresponse genes in both WT and corresponding mutants Plant hormone responses in Arabidopsis have been correlated with the expression of hormone-specific marker genes. We studied the expression of few such genes that are well documented to be induced by SA, JA/ET or ABA, both before and after treatment with EBR. PR-1, transcription factor WRKY70 and WAK1 are known to be regulated primarily by SA [35-37]; PDF1.2, LOX2 and HEL by JA/ET [38-40]; and RD22 and LTP4 by ABA [41,42].

The steady-state levels of PR-1, WRKY70 and WAK1 transcripts were elevated by EBR in WT and SA-related genotypes, including npr1-1, albeit at different levels (Figure 3A). The npr1-1 genotype is defective in the expression of $P R$ genes in response to SA [43]. Full-scale induction of WRKY70 and WAK1 by SA also requires a functional NPR1 $[36,37]$. Our results clearly indicate that
EBR can mediate induction of PR-1, WRKY70 and WAK1 to levels seen in Figure 3A in an NPR1-independent manner.

EBR treatment also enhanced the expression of the JA/ ET marker gene PDF1.2 in WT, aos, jar1-1 and eto1-1 backgrounds, but not to the same extent in ein2 (Figure $3 \mathrm{~B}$ and $3 \mathrm{C}$ ). The effect of EBR on LOX2 expression was distinct in Col and jar1-1 backgrounds, but not in Col-6 and aos backgrounds. Increase in the expression of the $H E L$ gene by EBR was only slight. The ABA-responsive LTP4 showed dramatic induction by EBR in WT and abi1-1 background (Figure 3D), but not in aba1-1. The transcript levels of the ABA-marker gene $R D 22$ were upregulated by EBR only slightly in aba1-1 and abi1-1 mutant seedlings, but significantly in WT (Figure 3D), indicating interaction between $\mathrm{ABA}$ and $\mathrm{BR}$ in affecting gene expression.

To determine the interaction of EBR with SA, JA/ET and $\mathrm{ABA}$ in the regulation of GST1, a gene common to 


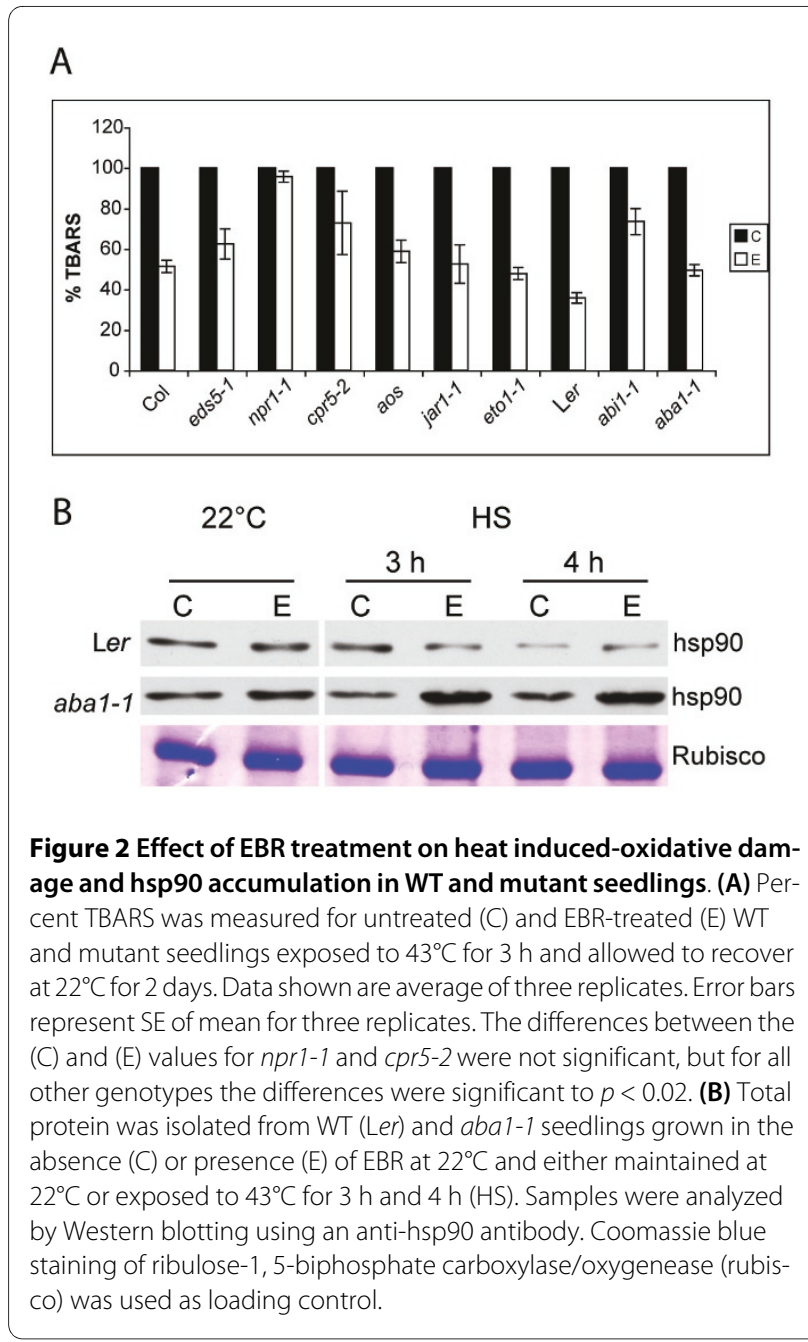

abiotic stress and defense pathways [44], we compared its transcript levels in untreated and EBR-treated WT and mutant seedlings. EBR enhanced GST1 transcript levels in SA (Figure 3E), as well as in all other hormone genotypes studied (data not shown). As would be expected, cpr5-2 had the highest expression of GST1 even in the absence of EBR.

Exogenous BR negatively regulates the BR biosynthetic gene DWF4 [6]. To ensure that transport, perception and signaling of BR is intact in npr1-1, which was most inert to EBR effects, DWF4 expression was determined in WT and npr 1-1. The fact that DWF4 levels were reduced in EBR-treated WT and npr1-1 seedlings as compared to untreated seedlings (Figure 3F) suggests that the BR pathway is intact in $n p r 1-1$.

Taken together, these results demonstrate that most, if not all, of the SA, JA/ET and ABA-responsive genes tested in the present study are also upregulated by BR both in WT and mutant backgrounds, albeit to different levels. These results point to overlapping gene targets of $\mathrm{ABA}, \mathrm{JA} / \mathrm{ET}$ or SA and BR, as well as to hormone interactions controlling the final output.

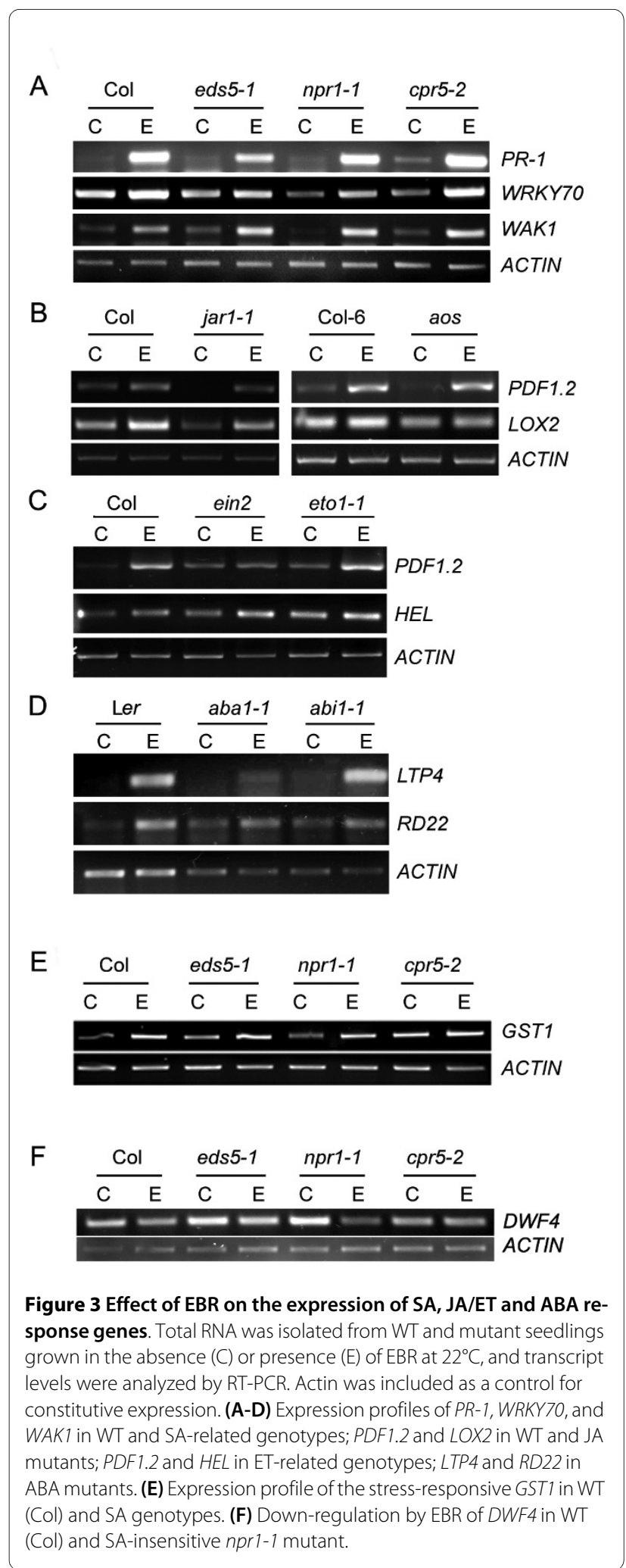

Upregulation of a subset of genes by EBR is likely via a BRregulated pathway

Since the effect of EBR on thermotolerance is best seen when plants are grown in the presence of EBR for 2-3 
weeks, the gene expression studies leading to Figure 3 were also conducted in plants receiving long-term exposure to EBR. To determine whether the JA/ET and ABAresponsive genes also respond to a short-term EBR treatment, we studied the expression of a subset of genes by qRT-PCR in response to a $7 \mathrm{~h}$ treatment with EBR. It is to be noted that BR effects on gene expression can take as long as $18-48 \mathrm{hrs}[45,46]$. Similar to the results of longterm treatment, the $7 \mathrm{~h}$ short-term treatment with EBR enhanced the transcript levels of PR-1 ( 2.9-fold), PDF1.2 ( 1.8-fold), RD22 ( 1.7-fold) and GST1 ( 2.9-fold), suggesting that changes in the expression of these genes likely occur via a BR-regulated pathway (Figure 4). Further studies are required to confirm this idea. Downregulation of DWF4 by exogenous $\mathrm{BR}$ was used as an experimental control (Figure 4).

\section{EBR rescues hypersensitivity of ein 2 to inhibition of germination by salt stress}

We have previously shown that EBR helps to overcome salt stress-induced inhibition of seed germination in $B$. napus [12]. More recently it was demonstrated that BRdeficient and BR signaling-defective mutants are more inhibited in germination on salt while a BRI1 overexpressing transgenic line is more resistant to salt than WT [23]. In this study, we first screened npr1-1, ein2, eto1-1, jar1-1 and abi1-1 mutants for their germination efficiency on $150 \mathrm{mM} \mathrm{NaCl}$. As noted before with ein2-5 [47], ein 2 was more sensitive to $\mathrm{NaCl}$-mediated inhibition of germination as compared to WT (Figure 5A and 5B). By contrast, eto1-1, npr1-1, jar1-1 and abi1-1 were less sensitive than WT (data not shown). Thus, to study the effects of EBR on salt stress we selected ein 2 because of its hypersensitivity to salt stress, and eto 1-1 and npr 1-1 because of their relatively higher susceptibility to HS even

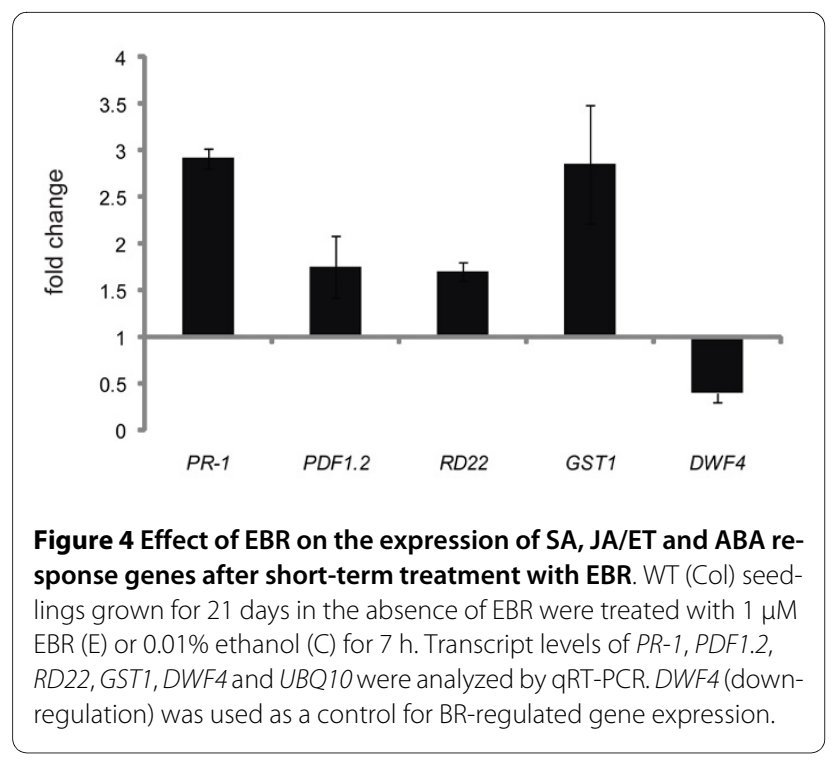

after EBR treatment. Seeds were allowed to germinate on $150 \mathrm{mM} \mathrm{NaCl}$ in the presence or absence of EBR, and seedlings with emerged cotyledons were scored after 3 days. Inhibition of germination of ein 2 seeds by salt was significantly reduced in the presence of EBR (Figure 5A and $5 \mathrm{~B}$ ). WT seeds showed germination rates of $55 \%$ and $>80 \%$ on $150 \mathrm{mM} \mathrm{NaCl}$ in the absence and presence of EBR, respectively, while ein2 seeds had germination rates of $\sim 10 \%$ and $80 \%$ under the same conditions (Figure $5 \mathrm{~B}$ ).

A

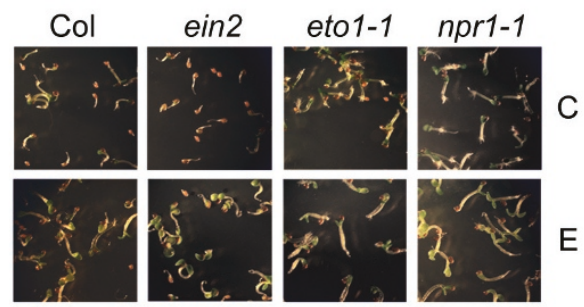

B

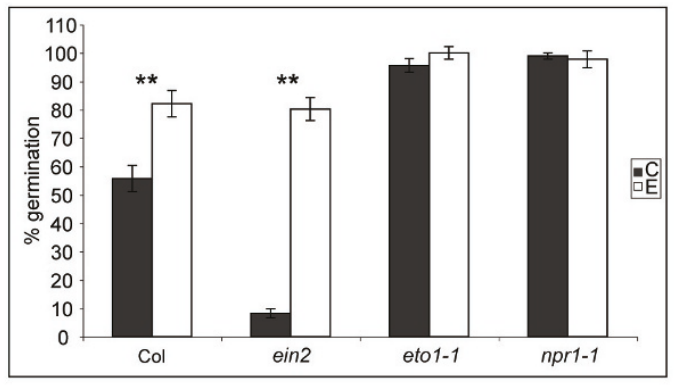

C

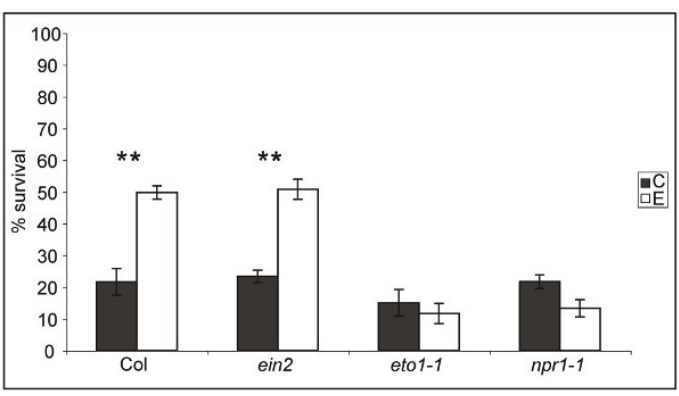

Figure 5 EBR effects on inhibition of germination by $\mathrm{NaCl}$ in WT and mutant seedlings. (A) WT (Col), ein2, eto 1-1 and npr1-1 were allowed to germinate on a nutrient medium containing $150 \mathrm{mM} \mathrm{NaCl}$ in the absence (C) or presence of $1 \mu \mathrm{M}$ EBR (E). Photographs of the seedlings were taken 3 days after imbibition. (B) Percentage of seeds germinated was calculated by counting the number of seedlings with emerged cotyledons at 3 days after imbibition. (C) Percentage of seedlings surviving on $150 \mathrm{mM} \mathrm{NaCl}$ was calculated by counting the number of seedlings that showed true leaves and green colour at 20 days after imbibition. All experiments were performed in triplicates with $n>$ 30. Error bars represent SE of mean for three replicates. Asterisks above the histograms indicate the significance of differences between un-

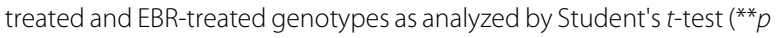
$<0.01)$ 
Seeds of eto1-1 and npr1-1 germinated at similar rates (> $90 \%$ ) on $150 \mathrm{mM} \mathrm{NaCl}$ in the absence or presence of EBR (Figure 5B). However, despite the good germination efficiency on salt, the average survival rates of eto1-1 and npr $1-1$ on salt were only 15 and $22 \%$, respectively (close to WT), but unlike WT, survival of the mutant seedlings could not be rescued by EBR treatment (Figure 5C). These results indicate that NPR1 has a role in salt stress and that BR effects on seedling survival under salt stress require a functional NPR1. Phenotypes of WT, ein2, eto11 and npr1-1 seedlings grown in the presence or absence of EBR under no-salt conditions can be seen in additional file 2: Pictures of 3-day-old seedlings.

\section{Discussion}

Feeding BR through roots (long-term treatment) not only rescues growth defects of BR-deficient mutants [48-50], but also leads to increased stress tolerance in WT seedlings [10-12]. Furthermore, overexpression of BR biosynthesis genes leads to increased vegetative and seed yield in transgenic seedlings [51]. In each case it is rationalized that BR-mediated outcomes likely involve both direct and indirect effects of BR. In the present study we focused on understanding BR interactions with other stress hormones in mediating increase in stress tolerance mainly because 1) BR is known to interact with other plant hormones in regulating plant developmental processes, and 2) multiple hormone signaling pathways play a role in acquisition of stress tolerance. We evaluated a subset of signaling, biosynthetic and constitutively active mutants of ABA, ET, JA and SA for thermo and salt tolerance in untreated and BR-treated states to assess the importance of these hormones in BR-mediated increase in stress tolerance of Arabidopsis seedlings. Here we demonstrate that NPR1, a protein well recognized for its role in SAmediated SAR and cross-talk inhibition of JA-mediated defense responses, also has a role in BR-mediated stress tolerance.

\section{Thermotolerance defects of hormone mutants and BR effects}

SA, and more recently JA, have been linked with thermotolerance. In case of SA genotypes, it is known that npr11 is compromised in basal thermotolerance, while cpr5-2 has greater thermotolerance than WT $[17,18]$. Recently it was demonstrated that a JAR1-dependent pathway is also required for basal thermotolerance [19]. Using a collection of genotypes with basal thermotolerance either lower or higher than WT, we found that EBR treatment could significantly increase the basic thermotolerance of these genotypes and that this increase was comparable to the increase in WT. An exception to this result within the SA, JA and ET genotypes was npr1-1, indicating that a functional NPR1 is required for full manifestation of BR's effects. Although collectively our data seems to suggest that BR is not critically dependent on SA levels and JA signaling for its antistress effects, further confirmation is required with genotypes such as Nahg and coil to make an unequivocal claim. Even if BR works to some extent independently of other hormones in conferring heat tolerance, the mere fact that ABA, BR, ET, JA and SA all play a role in thermotolerance of Arabidopsis plants suggests that there must be some redundant and some specific events in the mechanisms by which these hormones produce their effects. With the exception of BR where some information has been obtained [10-12], molecular changes mediated by ABA, ET, JA and SA that lead to thermotolerance are largely unknown. In case of ethylene, the Ethylene Response Factor Protein, JERF3, has been demonstrated to activate the expression of oxidative genes, resulting in decreased accumulation of ROS and, in turn, enhanced adaptation to drought, freezing, and salt in tobacco [52]. A similar role for JERF3 can be envisioned in response to HS. A number of ABA-regulated genes have been implicated in drought tolerance [16]. Recent functional characterization of the ABA-regulated ERD10 and ERD14 indicated that these proteins could prevent the heat-induced aggregation and/or inactivation of various enzyme substrates [53]. Thus, induction of genes functionally similar to molecular chaperones by ABA during HS may help combat the denaturing stress effects of HS.

Previous studies involving treatment with exogenous ABA [31], $a b a$ and $a b i$ mutants [17], and high ABA producing lines [54], have demonstrated the positive effects of ABA on thermotolerance. Under our experimental conditions the differences in the survival rates of untreated WT and aba1-1 and abi1-1 mutant seedlings were not striking, but the most pronounced effects of EBR with respect to survival within this set of plants was seen in aba1-1 seedlings (Figure 1F), indicating that endogenous ABA levels suppress BR effects. This notion is supported further by higher accumulation of hsp90, a representative of the hsp families of proteins that are known markers of thermotolerance, in aba1-1 seedlings as compared to WT (Figure 2B). It should be noted that neither SA, nor ABA or BR mutants are compromised in hsp accumulation $[12,17]$ [present study]. We have previously demonstrated that treatment with exogenous EBR can significantly increase hsp accumulation in B. napus $[10,11]$, but that this effect in Arabidopsis is subtle [12]. Thus, the clear enhancement of hsp accumulation in response to EBR during HS in aba1-1, but not in WT (Figure 2B), confirms that endogenous ABA levels suppress $B R$ effects in WT even under stress conditions. While this work was under preparation, a study describing $A B A$ inhibition of $B R$ signaling was reported whereby it was shown that $\mathrm{ABA}$ increases the expression levels of 
BR biosynthesis gene $D W F 4$ and $C P D$ to a greater extent in aba1 than in WT, reinforcing the idea that ABA inhibits $\mathrm{BR}$ signaling in WT and that this inhibition is relieved in the aba1 background [23].

Although BR and ABA display an antagonistic relationship in some physiological responses, we observed in a microarray experiment that several ABA-responsive genes and one $\mathrm{ABA}$ biosynthesis gene were upregulated by EBR and HS [P. Krishna and coworkers, unpublished results]. These results suggest that $A B A$ levels rise in response to HS in Arabidopsis and that this increase may be further augmented by BR treatment. Indeed, ABA content has been reported to increase in pea leaves in response to HS [55] and in response to BR under HS in $C$. vulgaris [30]. Based on these results it can be speculated that $B R$ augments $A B A$ levels and ABA-related effects during HS (Figure 6), but it is only when ABA levels are compromised that the BR effects of enhancing stress tolerance become apparent.

\section{NPR1, stress tolerance and BR effects}

Although npr1-1 seedlings have been shown to be defective in basal thermotolerance, the heat sensitivity of this genotype is not dramatically lower than WT [17-19]. However, in our study the mere 2.4-fold increase in percent survival of npr1-1 in response to EBR treatment as compared to the 9-fold increase in WT Col following HS (Figure 1), nearly no change in oxidative damage levels in

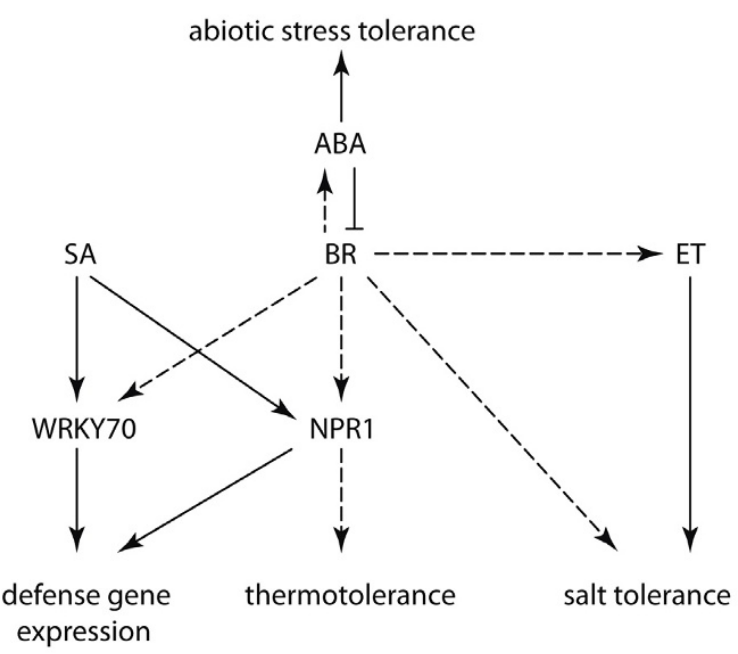

Figure 6 Proposed model for interaction of $B R$ with $S A, A B A$ and ET in mediating stress tolerance. BR positively regulates $S A$ pathway components NPR1 and WRKY70 to mediate thermotolerance and defense gene expression, respectively. ABA suppresses BR effects on thermotolerance, but BR may enhance $A B A$ responses under certain conditions by increasing $A B A$ levels. BR can enhance salt tolerance through an ET-independent pathway or ET-dependent pathway. The dashed arrows represent BR responses, while solid arrows indicate other hormone pathways. npr1-1 in response to EBR (Figure 2A), and the lack of EBR effect in increasing survival of npr1-1 seedlings on salt (Figure 5B), explicitly indicate that a functional NPR1 is required for the manifestation of $\mathrm{BR}$ effects on seedling stress tolerance. Two questions arise from these observations; 1) what would be the function of NPR1 during abiotic stress conditions, and 2) how could NPR1 integrate in the BR pathway?

NPR1 is a redox-controlled transcriptional cofactor, which is key to development of SAR and critical for modulating cross-talk between SA and JA signaling [56]. In the absence of stress, NPR1 is maintained in a large complex consisting of intermolecular disulfide bonded oligomers, which upon stress are reduced to an active monomeric state [57]. The monomeric form interacts with TGA-bZIP transcription factors and activates defense gene expression. ROS is a common signal in plant stress responses to both abiotic and biotic stresses $[58,59]$. The notion that ROS could be a signal for the HS response is derived from studies of activation of heat shock transcription factors (Hsfs). The eukaryotic Hsf1 multimerizes and binds to DNA upon either heating or oxidation with $\mathrm{H}_{2} \mathrm{O}_{2}$ [60]. More direct evidence showing that endogenous ROS production is necessary for induction of the HS response comes from the observation that a dominant negative allele of Rac1, the small GTPase necessary for the activation of ROS production by membrane-bound NADPH oxidase [61], inhibits the stressinduced activation of Hsf1 [62]. Thus, it is highly likely that ROS production during HS also activates NPR1, leading to gene expression changes critical for thermotolerance. Future studies directed at global gene expression analysis in WT and nprl mutant in response to HS and $\mathrm{BR}$ as separate and combined treatments should indicate NPR1-dependent molecular changes and help clarify the role of NPR1 in BR-mediated increase in thermotolerance.

The mechanism for how BR could function with NPR1, it is speculated that ROS-activated NPR1 monomers may bind a BR-activated regulator to affect stress-responsive gene expression critical to the survival of seedlings under stress conditions. It is unlikely that NPR1 controls BR signaling via BIN2 and BZR1 given that downregulation of DWF4 in npr1-1 was unaffected (Figure 3F).

\section{Oxidative stress state in cpr5 and BR effects}

The $c p r$ (CONSTITUTIVE EXPRESSOR OF PR GENES) mutants are characterized with increased concentrations of SA, constitutive expression of the $P R$ genes, and enhanced resistance to pathogens [63,64]. The cpr mutants are in a state of high-cellular oxidative stress state as compared to WT. For example, cprl plants exhibited greater oxidative damage than WT under both normal growth $\left(23^{\circ} \mathrm{C}\right)$ and chilling $\left(5^{\circ} \mathrm{C}\right)$ conditions [65], and 
molecular changes in cpr 5 such as increased expression of several genes in the ROS gene network, including GSTs, indicate that the cellular redox balance in this mutant is deregulated [66]. We also observed higher levels of GST1 transcript in cpr5-2 as compared to WT (Figure 3B). The high-cellular oxidative stress state of the $c p r$ mutants, combined with the constitutively activated SA and JA/ET-mediated pathways [64,67], may trigger not only defense responses against pathogens but also abiotic stress response pathways, leading to greater survival of cpr5-2 seedlings than WT in response to HS (Figure 1B). EBR treatment further enhanced the survival rates of cpr5-2 seedlings exposed to HS (Figure 1B), but had negligible effect on the oxidative damage levels in this mutant (Figure 2A), presumably due to the inherent oxidative state of the mutant. This result does not preclude other positive effects of EBR on cpr5-2 physiology, leading to increased stress tolerance.

\section{BR induces expression of other hormone marker genes}

Upregulation of $P R-1$ by BR in eds5-1 and npr1-1 backgrounds (Figure 3A), as well as in short-term treatment (Figure 4), suggests that BR directly mediates expression of this gene. Interestingly, we found WRKY70, a transcription factor acting downstream of NPR1 and involved in the expression of SA-induced $P R$ genes [36], to also be upregulated by BR in different SA genotypes (Figure 3A). Thus, in addition to NPR1, WRKY7O may be a potential point of cross-talk between SA and BR via which BR may induce a subset of SA-responsive genes. Hormone response data obtained using AtGenExpress Visualization Tool (AVT) http://jsp.weigelworld.org/expviz/ expviz.jsp indicate that SA and BR are the two most potent inducers of WRKY70 expression (data not shown), which reinforces the idea that WRKY7O is an overlapping transcriptional target of both SA and BR. Such a scenario could explain, in part, how BR enhances plant resistance against pathogen infection [2].

BR could increase the expression of PDF1.2 in JA mutants, but not to the same extent in the ET-insensitive mutant ein2 (Figure $3 \mathrm{~B}$ and $3 \mathrm{C}$ ). Thus, at present we favour the possibility that BR effects on PDF1.2 expression are mediated via the ET pathway. It should be noted that PR-1 and PDF1.2 genes are constitutively expressed in cpr and ssi1 mutants of Arabidopsis in an NPR1-independent, and SA, JA and ET-dependent manner [67,68], providing precedent for the notion that more than one pathway governs the expression of these genes. The increase in the transcript levels of the ABA-responsive $R D 22$ gene and the stress-induced GST1 gene in WT and hormone mutants by EBR, including short-term treatment of WT (Figure 4), suggests that these genes may also be primary targets of BR. Taken together, our data indicate that BR has regulatory inputs into the expression of other hormone-responsive genes, which may result from the action of the BR pathway either on the promoters of these genes, or on the regulation of a hormone-signaling component or the biosynthesis of another hormone (Figure 6).

\section{BR effects on inhibition of seed germination by salt}

We have previously shown in B. napus that EBR helps to overcome inhibition of seed germination by salt [12]. To study the involvement of BR and other hormones in salt tolerance, we screened WT, npr1-1, jar1-1, abi1-1, ein2 and eto1-1 seeds for germination on $150 \mathrm{mM}$ salt. The ein2-5 mutant has been found to be hypersensitive to salt [47] and ein2-1 displayed sensitivity to heat and osmotic stress [69]. Clearly, EIN2 is an important node for interaction of stress and hormonal signaling pathways. The fact that EBR could rescue hypersensitivity of ein2 to salt (Figure 5A and 5B) and increase survival rates of ein2 seedlings following HS (Figure 1) with effects paralleling those in WT, unambiguously indicates that BR can bypass ET signaling in conferring stress tolerance in Arabidopsis.

We included $n p r 1-1$ and eto1-1 in the salt stress study due to the hypersensitivity of these genotypes to HS even in presence of BR. Interestingly, while both npr1-1 and eto1-1 were insensitive to salt during germination, both genotypes had survival rates comparable with those of WT and ein2 in the absence of EBR, and notably lower survival rates than $\mathrm{WT}$ and ein 2 in the presence of EBR (Figure 5C). These results further endorse a crucial requirement of functional NPR1 in BR-mediated increase in stress tolerance and suggest further explorations of the roles of NPR1 in abiotic stress. The possibility that NPR1 mediates defense responses against abiotic stresses has been suggested in two recent reports [70,71].

\section{Conclusions}

In summary we have demonstrated that 1) BR-mediated increase in stress tolerance is integrated with other hormone pathways, 2) NPR1 appears to be a critical component of BR-mediated effects on thermo and salt tolerance, 3) ABA inhibits BR effects in abiotic stress responses, 4) the effect of $\mathrm{BR}$ in overcoming inhibition of germination by salt is independent of EIN2, and 5) several hormoneresponsive genes are also BR-responsive. Overall, these findings point to possible cross-talk of BR with SA, ET and $\mathrm{ABA}$ signaling pathways in mediating stress responses, as depicted in Figure 6.

\section{Methods}

\section{Plant material and growth conditions}

The eds5-1 (CS3735), npr1-1 (CS3726), cpr5-2 (CS3770), ein2 (CS8844), eto1-1 (CS3072), aos (CS6149), and jar1-1 mutants belong to the Col background, while the aba1-1 
(CS21) and abi1-1 (CS22) mutants are in the Ler background. Accordingly, the WT Col and Ler were used as controls in the experiments. The aos mutant is a T-DNA knock-out line derived from Col-6, hence its parental line (CS8155) was used as control. The jar1-1 mutant was a kind donation from Dr. Pradeep Kachroo (University of Kentucky, Lexington, KY, USA). All other mutants were obtained from the Arabidopsis Biological Resource Center (ABRC).

Seedlings were grown essentially as described by Kagale et al. [12]. Seeds were surface sterilized and plated on $1 \times$ Murashige and Skoog medium (Sigma, St. Louis) supplemented with B5 vitamins, 1\% (w/v) agar, 1\% sucrose, and either $1 \mu \mathrm{M}$ EBR or $0.01 \%$ ethanol (solvent for EBR). The plates were kept for 3 days in the dark at $4^{\circ} \mathrm{C}$ to encourage synchronized germination and then transferred to $22^{\circ} \mathrm{C}$ with a $16 / 8 \mathrm{~h}$ photoperiod $(80 \mu \mathrm{mol}$ $\mathrm{m}^{-2} \mathrm{~s}^{-1}$ ) and allowed to grow for 21 days. For the shortterm EBR treatment, 21-day-old seedlings grown in the medium without EBR were submerged for $7 \mathrm{~h}$ in sterile water containing $1 \mu \mathrm{M}$ EBR or $0.01 \%$ ethanol.

\section{Heat stress treatments}

The thermotolerance of Arabidopsis seedlings was assayed according to Kagale et al. [12] with minor modifications. Seedlings grown at $22^{\circ} \mathrm{C}$ for 21 days were exposed to $43^{\circ} \mathrm{C}$ for $4 \mathrm{~h}$ and scored as dead or surviving after 7 days of recovery at $22^{\circ} \mathrm{C}$. Seedlings that were completely bleached were considered dead and those with green leaves were considered surviving. Values in Figure 1B represent average percentages of data obtained in three biological replicates. Plant tissue was collected at different time points and quick-frozen for protein isolation and for the TBARS assay.

\section{Salt stress treatments}

Surface sterilized seeds were germinated on $0.5 \times$ Murashige and Skoog medium supplemented with B5 vitamins and either $1 \mu \mathrm{M}$ EBR or $0.01 \%$ ethanol. Salt treatment was given by including $150 \mathrm{mM} \mathrm{NaCl}$ in the medium. All plates were kept for 3 days in the dark at $4{ }^{\circ} \mathrm{C}$ plates and then transferred to $22^{\circ} \mathrm{C}$. Percent germination was determined 3 days after transferring plates to $22^{\circ} \mathrm{C}$. Seeds with emerging cotyledons were scored as germinated. Percent survival was calculated by counting the number of seedlings that showed green leaves at 20 days after imbibition. Values in Figure 5 are average percentages of data obtained in three biological replicates.

\section{TBARS assay}

TBARS assay was performed according to Heath and Packer [34]. Seedlings grown at $22^{\circ} \mathrm{C}$ for 21 days were subjected to $43^{\circ} \mathrm{C}$ for $3 \mathrm{~h}$ and then allowed to recover for 2 days at $22^{\circ} \mathrm{C}$. Seedlings were quick frozen in liquid nitrogen and $0.5 \mathrm{~g}$ of the tissue was ground in $1 \mathrm{~mL}$ of solution containing buffer 1 and buffer 2 in equal proportions (buffer 1: $0.5 \mathrm{~mL}$ of $0.5 \%(\mathrm{w} / \mathrm{v})$ thibarbituric acid in $20 \%(\mathrm{v} / \mathrm{v})$ trichloroacetic acid; buffer 2: $0.5 \mathrm{~mL} 175 \mathrm{mM}$ $\mathrm{Nacl}$ in $50 \mathrm{mM}$ Tris, $\mathrm{pH}$ 8.0). Ground samples were heated to $94^{\circ} \mathrm{C}$ for $1 \mathrm{~h}$, centrifuged at $13,000 \mathrm{rpm}$ for 20 min, and the absorbance of the supernatant was measured at 532 and $600 \mathrm{~nm}$. The levels of TBARS were deduced from the malonaldehyde standard curve and in each case the TBARS levels in the EBR-treated samples were compared to that of untreated control. Values in Figure 2A were averaged from three replicates.

\section{Protein extraction and western blotting}

Extraction of total proteins and western blotting were carried out as described by Dhaubhadel et al. [10]. Seedlings grown at $22^{\circ} \mathrm{C}$ for 21 days were either maintained at $22^{\circ} \mathrm{C}$ or subjected to $43^{\circ} \mathrm{C}$ for 3 and $4 \mathrm{~h}$. Seedling tissue above the medium was harvested, frozen in liquid nitrogen and stored at $-80^{\circ} \mathrm{C}$. Frozen tissue was ground in protein extraction buffer ( $25 \mathrm{mM}$ Tris-HCL, $1 \mathrm{mM}$ EDTA, 20 $\mathrm{mM} \mathrm{NaCl}, 1 \mathrm{mM}$ PMSF, $1 \mathrm{mM}$ benzamidine, $1 \mu \mathrm{g} / \mathrm{ml}$ leupeptin and $2 \mu \mathrm{g} / \mathrm{ml}$ aprotinin) and after centrifugation at $13,000 \mathrm{rpm}$ for $30 \mathrm{~min}$, the supernatant was transferred to a new tube. Protein concentration was determined by the bradford assay. Total proteins $(15 \mu \mathrm{g})$ were separated on a 7.5\% SDS-polyacrylamide gel and transferred onto nitrocellulose membrane by electroblotting using the Trans-blot Semi-Dry Electrophoretic Transfer Cell (BioRad, Hercules, CA, USA). Hsp90 was detected by sequential incubation with the polyclonal R2 antisera [72] and the peroxidase conjugated anti-rabbit IgG, each at a dilution of 1:5,000, followed by chemiluminescent detection (ECL system, Amersham, Baie d'Urfe, QC). Band densities were quantified by densitometry with NIH ImageJ software http://rsbweb.nih.gov/ij/.

\section{RT-PCR analysis}

RNA was extracted from 21-day-old seedlings grown at $22^{\circ} \mathrm{C}$ using the SV Total RNA Isolation System (Promega, Madison, WI). Total RNA ( $3 \mu \mathrm{g})$ was reverse transcribed using the oligo $(\mathrm{dT})_{18}$ primer and Super Script First Strand Synthesis System for RT-PCR (Invitrogen, Carlsbad, CA). PCR was carried out with an initial denaturation step of $94^{\circ} \mathrm{C}$ for $5 \mathrm{~min}$ followed by various cycles of denaturation $\left(40 \mathrm{~s}\right.$ at $\left.94^{\circ} \mathrm{C}\right)$, annealing $\left(45 \mathrm{~s}\right.$ at $\left.53^{\circ} \mathrm{C}\right)$, and extension $\left(45 \mathrm{~s}\right.$ at $\left.72^{\circ} \mathrm{C}\right)$. After the last cycle, a final extension was carried out for $5 \mathrm{~min}$ at $72^{\circ} \mathrm{C}$. PCR was performed for 32 cycles for PDF1.2, HEL, WRKY70, LTP4, RD22; 35 cycles for LOX2, PR-1, WAK1, GST1; and 21 cycles for ACTIN (control gene). For quantitative RTPCR (qRT-PCR) analysis, PCR reactions were performed using SYBR-Green I (Invitrogen, Carlsbad, CA) at $0.1 \times$ concentration and Rotor Gene-3000 thermal cycler (Cor- 
bett Research, Sydney, Australia) with an initial denaturation step at $94^{\circ} \mathrm{C}$ for $4 \mathrm{~min}$ followed by various cycles of denaturation $\left(15 \mathrm{~s}\right.$ at $\left.94^{\circ} \mathrm{C}\right)$, annealing $\left(30 \mathrm{~s}\right.$ at $\left.55^{\circ} \mathrm{C}\right)$ and extension $\left(30 \mathrm{~s}\right.$ at $72^{\circ} \mathrm{C}$ and $15 \mathrm{~s}$ at $\left.83^{\circ} \mathrm{C}\right)$. UBQ10 was used as control gene for qRT-PCR analysis. The primer sequences used for RT-PCR and qRT-PCR analysis are provided in additional file 3: List of primer sequences used.

\section{Additional material}

Additional file 1 Pictures of 21-day-old seedlings. WT, SA and ABA mutant seedlings grown on a nutrient medium in the absence (C) or presence of $1 \mu \mathrm{M}$ EBR (E) for 21 days under no-stress conditions.

Additional file 2 Pictures of 3-day-old seedlings. WT, ein2, eto 1-1 and npr1-1 mutant seedlings after 3 days of germination on a nutrient medium in the absence (C) or presence of $1 \mu \mathrm{M}$ EBR (E) under no-salt conditions.

\section{Additional file 3 List of primer sequences used}

\section{Authors' contributions}

UKD designed and carried out the experiments and drafted the manuscript. TR carried out the experiments involving ABA mutants, participated in manuscript preparation. PK is the instigator of the project; she participated in the design of the experiments and contributed to the writing and revision of the paper. All authors have read and approved the final manuscript.

\section{Acknowledgements}

This research was supported by the Natural Sciences and Engineering Research Council of Canada. We thank Dr. Pradeep Kachroo (University of Kentucky, Lexington, KY, USA) for kind donation of the jar1-1 mutant, the Arabidopsis Biological Resource Center (ABRC) for all other mutants, Harpreet Jammu for technical help, and Professor Mark Perry for careful reading of the manuscript.

\section{Author Details}

Department of Biology, University of Western Ontario, London, ON, N6A 5B7, Canada

Received: 29 June 2009 Accepted: 19 July 2010

Published: 19 July 2010

\section{References}

1. Sasse JM: Physiological actions of brassinosteroids: an update. J Plant Growth Regul 2003, 22:276-288.

2. Krishna P: Brassinosteroid-mediated stress responses. J Plant Growth Regul 2003, 22:289-297.

3. Divi UK, Krishna P: Brassinosteroids confer stress tolerance. In Plant stress biology: genomics goes systems biology Edited by: Hirt H. Weinheim: Wiley-VCH; 2009:119-135.

4. Vert G, Nemhauser JL, Geldner N, Hong F, Chory J: Molecular mechanisms of steroid hormone signaling in plants. Annu Rev Cell Dev Biol 2005, 21:177-201.

5. Belkhadir $Y$, Wang $X$, Chory J: Brassinosteroid signaling pathway. Sci STKE 2006, 364:. cm 4

6. He JX, Gendron JM, Sun Y, Gampala SS, Gendron N, Sun CQ, Wang ZY: $B Z R 1$ is a transcriptional repressor with dual roles in brassinosteroid homeostasis and growth responses. Science 2005, 307:1634-1638.

7. Yin Y, Vafeados D, Tao Y, Yoshida S, Asami T, Chory J: A new class of transcription factors mediates brassinosteroid-regulated gene expression in Arabidopsis. Cell 2005, 120:249-259.

8. Vailleau F, Daniel X, Tronchet M, Montillet JL, Triantaphylidès C, Roby D: A R2R3-MYB gene, AtMYB30, acts as a positive regulator of the hypersensitive cell death program in plants in response to pathogen attack. Proc Natl Acad Sci USA 2002, 99:10179-10184.

9. Yu X, Li L, Guo M, Chory J, Yin Y: Modulation of brassinosteroidregulated gene expression by Jumonji domain-containing proteins ELF6 and REF6 in Arabidopsis. Proc Natl Acad Sci USA 2008, 105:7618-7623.
10. Dhaubhadel S, Chaudhary S, Dobinson KF, Krishna P: Treatment with 24epibrassinolide, a brassinosteroid, increases the basic thermotolerance of Brassica napus and tomato seedlings. Plant Mol Biol 1999, 40:333-342.

11. Dhaubhadel S, Browning KS, Gallie DR, Krishna P: Brassinosteroid functions to protect the translational machinery and heat-shock protein synthesis following thermal stress. Plant J 2002, 29:681-691.

12. Kagale S, Divi UK, Krochko JE, Keller WA, Krishna P: Brassinosteroid confers tolerance in Arabidopsis thaliana and Brassica napus to a range of abiotic stresses. Planta 2007, 225:353-364.

13. Koh S, Lee SC, Kim MK, Koh JH, Lee S, An G, Choe S, Kim SR: T-DNA tagged knockout mutation of rice OsGSK1, an orthologue of Arabidopsis BIN2, with enhanced tolerance to various abiotic stresses. Plant Mol Biol 2007, 65:453-466

14. Nemhauser JL, Hong F, Chory J: Different plant hormones regulate similar processes through largely nonoverlapping transcriptional responses. Cell 2006, 126:467-475.

15. Bari R, Jones JD: Role of plant hormones in plant defence responses. Plant Mol Biol 2009, 69:473-488.

16. Zhu JK: Salt and drought stress signal transduction in plants. Annu Rev Plant Biol 2002, 53:247-273.

17. Larkindale J, Hall JD, Knight MR, Vierling E: Heat stress phenotypes of Arabidopsis mutants implicate multiple signaling pathways in the acquisition of thermotolerance. Plant Physiol 2005, 138:882-897.

18. Clarke SM, Mur LA, Wood JE, Scott IM: Salicylic acid dependent signaling promotes basal thermotolerance but is not essential for acquired thermotolerance in Arabidopsis thaliana. Plant J 2004, 38:432-447.

19. Clarke SM, Cristescu SM, Miersch O, Harren FJ, Wasternack C, Mur LA Jasmonates act with salicylic acid to confer basal thermotolerance in Arabidopsis thaliana. New Phytol 2009, 182:175-187.

20. Hardtke CS, Dorcey E, Osmont KS, Sibout R: Phytohormone collaboration: zooming in on auxin-brassinosteroid interactions. Trends Cell Biol 2007, 17:485-492.

21. Shimada A, Ueguchi-Tanaka M, Sakamoto T, Fujioka S, Takatsuto S, Yoshida S, Sazuka T, Ashikari M, Matsuoka M: The rice SPINDLY gene functions as a negative regulator of gibberellin signaling by controlling the suppressive function of the DELLA protein, SLR1, and modulating brassinosteroid synthesis. Plant J 2006, 48:390-402.

22. Steber $C M$, McCourt $P$ : A role for brassinosteroids in germination in Arabidopsis. Plant Physiol 2001, 125:763-769.

23. Zhang S, Cai Z, Wang X: The primary signaling outputs of brassinosteroids are regulated by abscisic acid signaling. Proc Nat/ Acad SciUSA 2009, 106:4543-4548.

24. Yi HC, Joo S, Nam KH, Lee JS, Kang BG, Kim WT: Auxin and brassinosteroid differentially regulate the expression of three members of the 1-aminocyclopropane-1-carboxylate synthase gene family in mung bean (Vigna radiata L.). Plant Mol Biol 1999, 41:443-454

25. Arteca JM, Arteca RN: Brassinosteroid-induced exaggerated growth in hydroponically grown Arabidopsis plants. Physiol Plant 2001, 112:104-112.

26. Ren C, Han C, Peng W, Huang Y, Peng Z, Xiong X, Zhu Q, Gao B, Xie D: A leaky mutation in DWARF4 reveals an antagonistic role of brassinosteroid in the inhibition of root growth by jasmonate in Arabidopsis. Plant Physiol 2009, 151:1412-1420.

27. Vert G, Walcher CL, Chory J, Nemhauser JL: Integration of auxin and brassinosteroid pathways by Auxin Response Factor 2. Proc Nat/ Acad Sci USA 2008, 105:9829-9834.

28. Li L, Xu J, Xu ZH, Xue HW: Brassinosteroids stimulate plant tropisms through modulation of polar auxin transport in Brassica and Arabidopsis. Plant Cell 2005, 10:2738-2753.

29. Kitanaga Y, Jian C, Hasegawa M, Yazaki J, Kishimoto N, Kikuchi S, Nakamura H, Ichikawa H, Asami T, Yoshida S, Yamaguchi I, Suzuki Y: Sequential regulation of gibberellin, brassinosteroid, and jasmonic acid biosynthesis occurs in rice coleoptiles to control the transcript levels of anti-microbial thionin genes. Biosci Biotechnol Biochem 2006, 70:2410-2419.

30. Bajguz A: Brassinosteroid enhanced the level of abscisic acid in Chlorella vulgaris subjected to short-term heat stress. J Plant Physiol 2009, 166:882-886.

31. Larkindale J, Knight MR: Protection against heat stress-induced oxidative damage in Arabidopsis involves calcium, abscisic acid, ethylene, and salicylic acid. Plant Physiol 2002, 128:682-695. 
32. Gaffney T, Friedrich L, Vernooij B, Negrotto D, Nye G, Uknes S, Ward E, Kessmann H, Ryals J: Requirement of salicylic acid for the induction of systemic acquired resistance. Science 1993, 261:754-756.

33. Feys BJF, Benedetti CE, Penfold CN, Turner JG: Arabidopsis mutants selected for resistance to the phytotoxin coronatine are male sterile, insensitive to methyl jasmonate, and resistant to a bacterial pathogen. Plant Cell 1994, 6:751-759.

34. Heath RL, Packer L: Photoperoxidation in isolated chloroplasts. I. Kinetics and stoichiometry of fatty acid peroxidation. Arch Biochem Biophys 1968, 125:189-198.

35. Uknes S, Mauch-Mani B, Moyer M, Potter S, Williams S, Dincher S, Chandler D, Slusarenko A, Ward E, Ryals J: Acquired resistance in Arabidopsis. Plant Cell 1992, 4:645-656.

36. Li J, Brader G, Palva ET: The WRKY70 transcription factor: a node of convergence for jasmonate-mediated and salicylate-mediated signals in plant defense. Plant Cell 2004, 16:319-331.

37. $\mathrm{He} \mathrm{ZH}, \mathrm{He} \mathrm{D}$, Kohorn BD: Requirement for the induced expression of a cell wall associated receptor kinase for survival during the pathogen response. Plant J 1998, 14:55-63.

38. Penninckx IA, Eggermont K, Terras FR, Thomma BP, De Samblanx GW, Buchala A, Métraux JP, Manners JM, Broekaert WF: Pathogen-induced systemic activation of a plant defensin gene in Arabidopsis follows a salicylic acid-independent pathway. Plant Cell 1996, 8:2309-2323.

39. Bell E, Creelman RA, Mullet JE: A chloroplast lipoxygenase is required for wound-induced jasmonic acid accumulation in Arabidopsis. Proc. Natl Acad Sci USA 1995, 92:8675-8679.

40. Potter S, Uknes S, Lawton K, Winter AM, Chandler D, DiMaio J, Novitzky R, Ward E, Ryals J: Regulation of a hevein-like gene in Arabidopsis. Mol Plant Microbe Interact 1993, 6:680-685.

41. Iwasaki T, Yamaguchi-Shinozaki K, Shinozaki K: Identification of a cisregulatory region of a gene in Arabidopsis thaliana whose induction by dehydration is mediated by abscisic acid and requires protein synthesis. Mol Gen Genet 1995, 247:391-398.

42. Arondel V, Vergnolle C, Catherine C, Kader J: : Lipid transfer proteins are encoded by small multigene family in Arabidopsis thaliana. Plant Sci 2000, 157:1-12

43. Cao H, Bowling SA, Gordon AS, Dong X: Characterization of an Arabidopsis Mutant That Is Nonresponsive to Inducers of Systemic Acquired Resistance. Plant Cell 1994, 6:1583-1592.

44. Wagner U, Edwards R, Dixon DP, Mauch F: Probing the diversity of the Arabidopsis glutathione S-transferase gene family. Plant Mol Biol 2002, 49:515-532.

45. Zurek DM, Rayle DL, McMorris TC, Clouse SD: Investigation of Gene Expression, Growth Kinetics, and Wall Extensibility during Brassinosteroid-Regulated Stem Elongation. Plant Physiol 1994 104:505-513.

46. Dhaubhadel S, Krishna P: Identification of Differentially Expressed Genes in Brassinosteroid-Treated Brassica napus Seedlings. J Plant Growth Regul 2008, 27:297-308.

47. Wang Y, Liu C, Li K, Sun F, Hu H, Li X, Zhao Y, Han C, Zhang W, Duan Y, Liu M, Li X: Arabidopsis EIN2 modulates stress response through abscisic acid response pathway. Plant Mol Biol 2007, 64:633-664.

48. Kauschmann A, Jessop A, Koncz C, Szekeres M, Willmitzer L, Altmann T: Genetic evidence for an essential role of brassinosteroids in plant development. Plant J 1996, 9:701-713.

49. Szekeres M, Németh K, Koncz-Kálmán Z, Mathur J, Kauschmann A, Altmann T, Rédei GP, Nagy F, Schell J, Koncz C: Brassinosteroids rescue the deficiency of CYP90, a cytochrome P450, controlling cell elongation and de-etiolation in Arabidopsis. Cell 1996, 85:171-182.

50. Fujioka S, Li J, Choi YH, Seto H, Takatsuto S, Noguchi T, Watanabe T, Kuriyama H, Yokota T, Chory J, Sakurai A: The Arabidopsis deetiolated2 Mutant Is Blocked Early in Brassinosteroid Biosynthesis. Plant Cell 1997, 9:1951-1962.

51. Choe S, Fujioka S, Noguchi T, Takatsuto S, Yoshida S, Feldmann KA: Overexpression of DWARF4 in the brassinosteroid biosynthetic pathway results in increased vegetative growth and seed yield in Arabidopsis. Plant J 2001, 26:573-582.

52. Wu L, Zhang Z, Zhang H, Wang XC, Huang R: Transcriptional modulation of ethylene response factor protein JERF 3 in the oxidative stress response enhances tolerance of tobacco seedlings to salt, drought, and freezing. Plant Physiol 2008, 148:1953-1963.
53. Kovacs D, Kalmar E, Torok Z, Tompa P: Chaperone Activity of ERD10 and ERD14, Two Disordered Stress-Related Plant Proteins. Plant Physiol 2008, 147:381-390.

54. Ristic Z, Cass DD: Chloroplast structure after water and hightemperature stress in two lines of maize that differ in endogenous levels of abscisic acid. Int J Plant Sci 1992, 153:186-196.

55. Liu HT, Liu YY, Pan QH, Yang HR, Zhan JC, Huang WD: Novel interrelationship between salicylic acid, abscisic acid, and PIP2-specific phospholipase $C$ in heat acclimation-induced thermotolerance in pea leaves. J Exp Bot 2006, 57:3337-3347.

56. Spoel SH, Koornneef A, Claessens SM, Korzelius JP, Van Pelt JA, Mueller MJ, Buchala AJ, Metraux JP, Brown R, Kazan K, Van Loon LC, Dong X, Pieterse CM: NPR1 modulates cross-talk between salicylate- and jasmonatedependent defense pathways through a novel function in the cytosol. Plant Cell 2003, 15:760-770.

57. Mou Z, Fan W, Dong X: Inducers of Plant Systemic Acquired Resistance Regulate NPR1 Function through Redox Changes. Cell 2003, 113:935-944.

58. Apel K, Hirt H: REACTIVE OXYGEN SPECIES: Metabolism, Oxidative Stress, and Signal Transduction. Annu Rev Plant Biol 2004, 55:373-399.

59. Dietz KJ: Redox signal integration: from stimulus to networks and genes. Physiol Plant 2008, 10:459-468.

60. Ahn SG, Thiele DJ: Redox regulation of mammalian heat shock factor 1 is essential for Hsp gene activation and protection from stress. Genes Dev 2003, 17:516-528.

61. Abo A, Pick E, Hall A, Totty N, Teahan C, Segal A: Activation of the NADPH oxidase involves the small GTP-binding protein p21 rac1. Nature 1991, 353:668-670.

62. Ozaki M, Deshpande S, Angkeow P, Suzuki S, Irani K: Rac1 Regulates Stress-induced, Redox-dependent Heat Shock Factor Activation. J Biol Chem 2000, 275:35377-35383.

63. Bowling SA, Guo A, Cao H, Gordon AS, Klessig DF, Dong X: A mutation in Arabidopsis that leads to constitutive expression of systemic acquired resistance. Plant Cell 1994, 6:1845-1857.

64. Bowling SA, Clarke JD, Liu Y, Klessig DF, Dong X: The cpr5 mutant of Arabidopsis expresses both NPR1-dependent and NPR1-independent resistance. Plant Cell 1997, 9:1573-1584.

65. Scott IM, Clarke SM, Wood JE, Mur LA: Salicylate accumulation inhibits growth at chilling temperature in Arabidopsis. Plant physiol 2004, 135:1040-1049.

66. Jing HC, Hebeler R, Oeljeklaus S, Sitek B, Stühler K, Meyer HE, Sturre MJ, Hille J, Warscheid B, Dijkwel PP: Early leaf senescence is associated with an altered cellular redox balance in Arabidopsis cpr5/old 1 mutants. Plant Biol (Stuttg) 2008, 10:85-98.

67. Clarke JD, Volko SM, Ledford H, Ausubel FM, Dong X: Roles of salicylic acid, jasmonic acid, and ethylene in cpr-induced resistance in arabidopsis. Plant Cell 2000, 12:2175-2190.

68. Nandi A, Kachroo P, Fukushige H, Hildebrand DF, Klessig DF, Shah J: Ethylene and jasmonic acid signaling affect the NPR1-independent expression of defense genes without impacting resistance to Pseudomonas syringae and Peronospora parasitica in the Arabidopsis ssi1 mutant. Mol Plant Microbe Interact 2003, 16:588-599.

69. Suzuki N, Rizhsky L, Liang H, Shuman J, Shulaev V, Mittler R: Enhanced tolerance to environmental stress in transgenic plants expressing the transcriptional coactivator multiprotein bridging factor 1c. Plant Physio/ 2005, 139:1313-1322.

70. Quilis J, Peñas G, Messeguer J, Brugidou C, San Segundo B: The Arabidopsis AtNPR1 inversely modulates defense responses against fungal, bacterial, or viral pathogens while conferring hypersensitivity to abiotic stresses in transgenic rice. Mol Plant Microbe Interact 2008, 21:1215-1231

71. Yasuda M, Ishikawa A, Jikumaru Y, Seki M, Umezawa T, Asami T, Maruyama-Nakashita A, Kudo T, Shinozaki K, Yoshida S, Nakashita H: Antagonistic interaction between systemic acquired resistance and the abscisic acid-mediated abiotic stress response in Arabidopsis. Plant Cell 2008, 20:1678-1692.

72. Krishna P, Reddy RK, Sacco M, Frappier JR, Felsheim RF: Analysis of the native forms of the $90 \mathrm{kDa}$ heat shock protein (hsp90) in plant cytosolic extracts. Plant Mol Biol 1997, 33:457-466

73. Glazebrook J, Rogers EE, Ausubel FM: Isolation of Arabidopsis mutants with enhanced disease susceptibility by direct screening. Genetics 1996, 143:973-982. 
74. Rogers E, Ausubel FM: Arabidopsis enhanced disease susceptibility mutants exhibit enhanced susceptibility to several bacterial pathogens and alterations in PR-1 gene expression. Plant Cell 1997, 9:305-316.

75. Nawrath C, Métraux JP: Salicylic acid induction-deficient mutants of Arabidopsis express $P R-2$ and $P R-5$ and accumulate high levels of camalexin after pathogen inoculation. Plant Cell 1999, 11:1393-1404

76. Delaney TP, Friedrich L, Ryals JA: Arabidopsis signal transduction mutant defective in chemically and biologically induced disease resistance. Proc Natl Acad Sci USA 1995, 92:6602-6606.

77. Guzman P, Ecker JR: Exploiting the triple response of Arabidopsis to identify ethylene-related mutants. Plant Cell 1990, 2:513-523.

78. Park JH, Halitschke R, Kim HB, Baldwin IT, Feldmann KA, Feyereisen R: A knock-out mutation in allene oxide synthase results in male sterility and defective wound signal transduction in Arabidopsis due to a block in jasmonic acid biosynthesis. Plant J 2002, 1:1-12.

79. Staswick PE, Su W, Howell SH: Methyl jasmonate inhibition of root growth and induction of a leaf protein in an Arabidopsis thaliana mutant. Proc Natl Acad Sci USA 1992, 89:6837-6840

80. Koornneef M, Jorna ML, Brinkhorst-van der Swan DLC, Karssen CM: The isolation of abscisic acid (ABA) deficient mutants by selection of induced revertants in nongerminating gibberellin sensitive lines of Arabidopsis thaliana (L.) Heynh. Theor App/ Genet 1982, 61:385-393.

81. Koornneef M, Reuling G, Karssen CM: The isolation and characterization of abscisic acid-insensitive mutants of Arabidopsis thaliana. Physiol Plant 1984, 61:377-383.

doi: 10.1186/1471-2229-10-15

Cite this article as: Divi et al., Brassinosteroid-mediated stress tolerance in Arabidopsis shows interactions with abscisic acid, ethylene and salicylic acid pathways BMC Plant Biology 2010, 10:151

Submit your next manuscript to BioMed Central and take full advantage of:

- Convenient online submission

- Thorough peer review

- No space constraints or color figure charges

- Immediate publication on acceptance

- Inclusion in PubMed, CAS, Scopus and Google Scholar

- Research which is freely available for redistribution

Submit your manuscript at www.biomedcentral.com/submit
C Biomed Central 